19 Revue d'histoire du XIXe siècle

Société d'histoire de la révolution de 1848 et des

révolutions du XIXe siècle

39 | 2009

Le monde de l'imprimé: des territoires aux acteurs -

Education et politique - Histoires politiques

Nathalie JAKOBOWICZ, 1830. Le peuple de Paris. Révolution et représentations sociales

Collection Histoire, Rennes, Presses universitaires de Rennes, 2009, 363 p. ISBN : 978-2-753508460. 20 euros.

Jean-Claude Caron

\title{
CpenEdition
}

Journals

Édition électronique

URL : http://journals.openedition.org/rh19/3953

DOI : $10.4000 /$ rh 19.3953

ISSN : $1777-5329$

Éditeur

La Société de 1848

Édition imprimée

Date de publication : 10 décembre 2009

Pagination : 165-167

ISSN : 1265-1354

Référence électronique

Jean-Claude Caron, «Nathalie JAKOBOWICZ, 1830. Le peuple de Paris. Révolution et représentations sociales », Revue d'histoire du XIXe siècle [En ligne], 39 | 2009, mis en ligne le 26 mars 2010, consulté le 22 septembre 2020. URL : http://journals.openedition.org/rh19/3953 ; DOI : https://doi.org/10.4000/ rh19.3953

Ce document a été généré automatiquement le 22 septembre 2020.

Tous droits réservés 


\section{Nathalie JAKOBOWICZ, 1830. Le peuple de Paris. Révolution et représentations sociales}

Collection Histoire, Rennes, Presses universitaires de Rennes, 2009, 363 p. ISBN : 978-2-753508460. 20 euros $^{1}$.

\section{Jean-Claude Caron}

12009 est une année éditoriale faste pour 1830, avec cet ouvrage qui paraît parallèlement à celui de Sylvie Vielledent sur 1830 aux théâtres (dont on lira un compte rendu à la suite de celui-ci). Réinterroger 1830 s'avère nécessaire, dans la mesure où la révolution de Juillet constitue, à bien des égards, une rupture fondamentale dans l'histoire contemporaine de la France. Le peuple surgit alors sur la scène publique et devient l'objet d'une représentation abondante et diverse par ses supports, ceux-là mêmes que l'auteure, à côté des sources archivistiques et imprimées habituelles, utilise: images (avec 1328 références), chansons, pièces de théâtre, brochures, journaux, canards, etc. On ne peut que se féliciter que l'ouvrage soit illustré d'une quarantaine d'images, dont certaines rarement reproduites, tout en regrettant l'absence d'une table de ces reproductions.

2 La première partie, consacrée à la représentation du peuple à la fin de la Restauration donne à voir les figures contradictoires qui sont alors élaborées. Menaçant, sauvage, voire violent ou criminel-né, le peuple est l'objet d'une étroite et quotidienne surveillance policière. C'est le peuple des faubourgs. Mais si Saint-Marcel est dépeint comme le plus répugnant, abritant un peuple souterrain de chiffonniers et de mendiants, tel n'est pas le cas de Saint-Antoine, quartier d'un peuple d'hommes de métiers. Nathalie Jakobowicz se penche sur le thème du compagnonnage, en particulier à travers la représentation du compagnon au théâtre, ou encore le thème des petits métiers ou des cris de Paris, objet d'une abondante iconographie. Toutes représentations qui nourrissent un imaginaire social et, malgré des déplacements et des évolutions, typifient les catégories abordées. En resserrant l'analyse sur L'Homme $d u$ peuple (1829), à la fois roman - dû à Touchard-Lafosse - et pièce de théâtre, 
l'auteure étudie de manière précise les mécanismes de production, de censure, de réception d'une œuvre qui nourrit un intense débat sur le "peuple».

La deuxième partie consacrée au «peuple nation » qui naît sur les barricades de Juillet, s'appuie sur un important corpus iconographique analysé avec précision par Nathalie Jakobowicz. Il ressort de cette analyse que le «peuple » représenté prend la figure des classes populaires, ou industrielles comme on dit alors, ou des «faubourgs ». Mais ce sont aussi les «Parisiens» dans leur ensemble qui sont loués pour avoir à la fois renversé l'absolutisme rampant de Charles $\mathrm{X}$ et maintenu l'ordre social, en faisant respecter la propriété. Nathalie Jakobowicz souligne à juste titre l'importance du thème de la fraternité en juillet 1830 et l'étend à sa dimension familiale. Le peuple est plus que vertueux: il est la vertu incarnée, étant entendu que cette dernière est surtout rapportée à la probité des combattants, à leur désintéressement et à leur respect de la propriété. Et plus encore le peuple est salué pour la rapidité avec laquelle il met fin à la révolution (la hantise de 1789 et de ses prolongements jusqu'à la Terreur est présente) et retourne à ses ateliers. Mais il existe des voix discordantes et le thème de la «fureur populaire » apparaît alors.

4 En terminant son étude avec «les peuples de l'automne ", Nathalie Jakobowicz peut ainsi observer la mise en place du «brouillage des identités populaires ». L'impact social de la crise économique nourrit la protestation populaire. L'émeute inquiète les autorités, le peuple devient menace. Mais chaque courant de pensée élabore son peuple. Du côté des opposants à la monarchie orléaniste, le peuple représenté devient le porte-parole de la révolution usurpée par les « gros » au détriment des combattants de Juillet, devenus des dupes. La curée, les budgétivores, les nouveaux courtisans sont opposés au peuple souffrant, du fait du chômage, du machinisme, des impôts, etc. Le contrefeu de la moralisation de la classe ouvrière est alors allumé par des élites sociales qui entendent agir par le biais de l'instruction populaire, mais aussi des outils culturels associés au peuple (chanson, théâtre). Mais l'automne 1830 est marqué par de nombreux épisodes de violentes manifestations (Pologne, procès des ministres de Charles $\mathrm{X}$ ) qui sont à l'occasion interprétés (ou instrumentalisés) comme annonciateurs d'une nouvelle Terreur.

5 Nathalie Jakobowicz accorde à juste titre une place importante à l'image. Son analyse iconographique aurait parfois gagné à être davantage croisée avec celle des textes qui sont produits au même moment, pour mettre en lumière des points communs ou d'éventuels contrastes. Sur le peuple au féminin, le peuple-enfant ou le peuple-jeune, on aimerait en savoir plus, comme sur le "peuple républicain » de Juillet 1830 ou l'apparition du «sujet démocratique ». Certaines généralisations seraient à nuancer : quelles sources, par exemple, permettent d'affirmer que « dès son arrivée au pouvoir, Charles X est reçu assez froidement par la population française »? De même, certaines affirmations sont discutables : "Contrairement à ce qui se passe pendant la Grande Révolution, où la fraternité s'est laissée gagner par la violence, les journées de Juillet ne connaissent pas cette dérive ", lecture un peu rapide d'une période et d'une notion qui auraient mérité d'être davantage approfondies.

$6 \mathrm{Au}$ total, cet ouvrage constitue indéniablement un jalon important dans l'historiographie de la révolution de 1830. Le cadre idéal d'une thèse, la chronologie volontairement limitée et l'espace aussi, malgré quelques prolongements provinciaux, ont rendu possible l'entreprise. Et même si l'emprise de la lecture culturaliste de l'événement peut être l'objet d'un débat, le contrepoint attendu d'une lecture 
sociopolitique du sujet étudié étant insuffisamment mis en œuvre, il n'en reste pas moins que ce Peuple de Paris comble un vide. Son auteure témoigne d'une rare sensibilité interprétative, qui met en œuvre des méthodologies adaptées - et maîtrisées - face à une documentation très riche et très variée. Il convient donc de remercier Nathalie Jakobowicz d'avoir produit un ouvrage dont les multiples qualités en font une référence sur la question.

\section{NOTES}

1. . Voir, du même auteur, dans ce numéro, «Les pratiques d'affichage dans l'espace public à Paris en 1830 », p. 17-36. 